\title{
Effect of a community-based intervention on nutritional behaviour in a developing country setting: the Isfahan Healthy Heart Programme
}

\author{
Noushin Mohammadifard ${ }^{1, *}$, Roya Kelishadi ${ }^{2}$, Morteza Safavi $^{3}$, Nizal Sarrafzadegan ${ }^{2}$, \\ Firoozeh Sajadi ${ }^{1}$, Gholam Hosein Sadri ${ }^{4}$, Maryam Maghroon ${ }^{1}$, Hasan Alikhasi ${ }^{1}$, \\ Said Heydari ${ }^{5}$ and Fereshteh Sarmadi ${ }^{6}$ \\ ${ }^{1}$ Nutrition Department, Isfahan Cardiovascular Research Center, Isfahan University of Medical Sciences, PO Box \\ 81465-1 148, Isfahan, Iran: ${ }^{2}$ Isfahan Cardiovascular Research Center, Isfahan University of Medical Sciences, \\ Isafahan, Iran: ${ }^{3}$ Nutrition Department, Faculty of Health, Isfahan University of Medical Sciences, Isfahan, Iran: \\ ${ }^{4}$ Isfahan University of Medical Sciences, Isfahan, Iran: ${ }^{5}$ Markazi Provincial Health Center, Arak University of \\ Medical Sciences, Arak, Iran: ${ }^{6}$ Najaf Abad Health Center, Najaf Abad, Isfahan University of Medical Sciences, \\ Isafahan, Iran
}

Submitted 28 June 2007: Accepted 28 0ctober 2008: First published online 17 February 2009

\begin{abstract}
Objective: The present study was conducted to determine the impact of a community-based intervention on the nutritional behaviour of a representative sample of Iranian adults.

Design: The Isfahan Healthy Heart Programme (IHHP), a six-year, action-oriented, integrated community-based study aimed at health promotion through the reduction of CVD risk factors, targeted the whole population living in two intervention cities, and compared outcomes with the population of a non-intervention city considered as reference. Dietary interventions were performed as educational, environmental and/or legislative strategies. A global dietary index (GDI) was calculated representing the general dietary behaviour. In addition, two consumption indices were calculated for specific food groups, i.e. meat products and major sources of fat. Univariate AVOVA was conducted to evaluate the impact of the intervention on dietary behaviours.

Setting: Isfahan and Najaf-Abad (intervention cities) and Arak (reference city), central Iran.

Subjects: The baseline survey was conducted among 12514 randomly selected adults aged $\geq 19$ years in both intervention and reference areas. The survey was repeated annually among about 5000 persons (2002-2005) in the intervention and reference communities.

Results: According to significant year $\times$ group interactions in mean fat consumption index (FCI) and meat consumption index (MCI) in the total population, a significant improvement in FCI and MCI was found in the intervention areas $v$. the reference area $(P<0 \cdot 001)$. In addition, the GDI improved significantly in the intervention areas $v$. the reference area $(P<0 \cdot 001)$.

Conclusions: The IHHP interventions were effective in improving dietary behaviours at the population level. The highest effectiveness was documented in the change in the type of fat consumed. Such simple and integrated interventions can be adopted in other developing countries with limited financial resources.
\end{abstract}

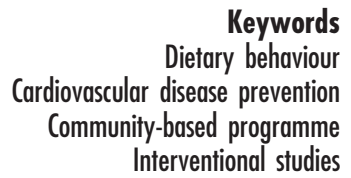

Keywords Cardiovascular disease prevention Interventional studies
Over the past 20 years, the incidence of non-communicable diseases (NCD) and especially CVD has changed, with a significant decline in industrialized countries and a rise in developing countries including those in the Eastern Mediterranean region ${ }^{(1)}$. Iran is an Eastern Mediterranean country in which the population has adopted a more Westernized lifestyle with respect to nutrition habits, smoking and physical inactivity. This adoption has led to a higher prevalence of CVD risk factors among the Iranian population ${ }^{(2)}$. CVD has emerged as the leading cause of mortality in Iran over the last decade ${ }^{(3)}$. Several effective and successful intervention programmes in industrialized countries, targeting CVD risk factors, have resulted in decreasing prevalence of CVD events ${ }^{(4-6)}$. These have been rare in developing countries. 
The Isfahan Healthy Heart Programme (IHHP) - a long-term, community-based intervention programme for health promotion through the reduction of CVD risk factors and hence CVD-induced morbidity and mortality was conducted in two intervention cities (Isfahan and Najaf-Abad) and one reference city (Arak) ${ }^{(7)}$ in Iran. One of the main objectives of the IHHP was to improve health behaviours, such as dietary behaviour, of the general population, and so dietary patterns were assessed annually in both the intervention and the reference $\operatorname{areas}^{(7)}$ to assess achievement of this aim.

In recent years, major works on dietary assessment have measured diet quality from diverse perspectives and in a comprehensive method. Many studies suggest that measuring diet complexity is the preferred choice to use of a single nutrient from foods to measure diet quality ${ }^{(8,9)}$. Overall diet scores have been associated with diet-related plasma biomarkers ${ }^{(10)}$ and are more strongly associated with risk of disease than are single nutrients ${ }^{(11)}$.

Several such overall diet scores have been developed, including the Diet Quality Index ${ }^{(12)}$, the Healthy Eating Index ${ }^{(10)}$ and the Global Dietary Index ${ }^{(13)}$. The present paper reports the results of the impact evaluation of the IHHP interventions on adults' dietary behaviours after four years of the programme. Also, we test the hypothesis that change in dietary behaviour will vary based on settlement (rural and urban) and gender.

\section{Methods and materials}

\section{Brief description of the programme}

The IHHP long-term objectives are to decrease the incidence, disability and mortality of NCD. The short-term objectives are to improve knowledge, attitude and practice in the general population and health professionals about the causes and outcomes of NCD, improving their skills to control risk factors. The IHHP objectives are described in more detail elsewhere ${ }^{(7)}$.

The study was done in two intervention areas (Isfahan and Najaf-Abad, a city neighbouring Isfahan) and one reference area (Arak), all located in central Iran. According to the National Census in 2000, the population was 1895856 and 275084 in Isfahan and Najaf-Abad, respectively. Arak, located $375 \mathrm{~km}$ north-west of Isfahan with 668531 population, was selected as reference area because of the similarity of its socio-economic, demographic and health profile with the intervention areas and good cooperation $^{(7)}$. A major baseline cross-sectional survey was conducted in 12514 randomly selected adults aged $\geq 19$ years and equally in both the intervention and the reference areas based on sex, age and settlement distributions in each community. About 5-10\% of households in these clusters were randomly selected. One person aged $\geq 19$ years per household was randomly selected if Iranian and mentally competent and if not pregnant for women ${ }^{(7)}$.
After the survey in 2001, a five-year intervention programme was started in August 2002 in urban and rural areas of Isfahan and Najaf-Abad. The interventions continued until 2006. Multistage random sampling and agebased Countrywide Integrated Non-communicable Disease Intervention (CINDI) protocol sampling methods ${ }^{(14)}$ were used for the baseline and subsequent annual surveys in both intervention and reference areas. Arak was evaluated as a reference area without any intervention.

\section{The intervention activities}

After analysing the results of the initial primary survey, we assessed the priorities and needs, and defined our objectives. Then, existing human and economic resources were used and set projects and strategies to emphasize tobacco control, healthy diet, physical activity and stress management based on different target groups. IHHP strategies have integrated activities in different fields of the health sector such as health promotion, disease prevention, treatment and rehabilitation. Key strategies for the interventional activities include public education through mass media, intersectional co-operation and collaboration, health professional education and involvement, marketing and organizational development, legislation and coordination, policy making, research and evaluation. Specific interventional activities are described elsewhere ${ }^{(7)}$. The IHHP targeted healthy nutrition, increased physical activity, tobacco control and stress management.

The programme includes ten distinct projects with different target groups, including: the Women's Healthy Heart Project, Heart Health Promotion in Children, the Health Professional Education Project, the Youth Healthy Heart Project, the Worksite Intervention Project, Healthy Lifestyles for High Risk Groups, Healthy Food for Healthy Communities, Isfahan Exercise and Air Pollution Control Project, Non Governmental Organizations (NGOs) and Volunteer Intervention Project, and Healthy Lifestyle for Cardiac Patients. Each project is managed by a directors committee including academics, health professionals, stakeholders and policy makers, and are involved in planning, implementing and evaluating their projects. An underlying principle in all ten projects is to develop and maintain close contact with representatives of relevant community organizations. IHHP teams work intensively and closely with representatives of the mass media, health professionals, business and market leaders (food industry, groceries, bakeries, fast-food shops), key NGO staff, and local political decision makers. The Mayor, Governor and Governor General of Isfahan and Najaf-Abad are involved in IHHP and the Isfahan Governor General is the honorary president of the IHHP. Among the nutrition activities, the population has learned to: (i) substitute hydrogenated oil and ghee with liquid oil and olive oil to minimize consumption of trans fatty acids; (ii) increase consumption of fruit and vegetables, fish and soya protein; (iii) decrease consumption of sausages, animal fat, sweets and soft 
drinks; and (iv) consume low-fat dairy products. Details of the interventions are described elsewhere ${ }^{(7)}$.

\section{Evaluation design}

The IHHP was conducted as an action-oriented, quasiexperimental demonstration programme with ongoing evaluation. This programme included three phases: pre, during and post intervention, all of which have been described previously ${ }^{(7)}$.

The IHHP impact evaluation was done with four annual independent sample surveys and a 10-year longitudinal cohort sample survey, to compare the levels of modifiable risk factors for NCD in the intervention and reference areas before, during and after the implementation of the interventions. To our knowledge, there is no evidence of a similar comprehensive, integrated, community-based intervention NCD prevention programme in a developing country which used a quasi-experimental design and with different levels of evaluation.

Data on physical and biochemical measurements were collected in the intervention and reference areas in the same studies on independent samples in the post intervention phase in $2006^{(7)}$.

Short-term impacts of IHHP interventions on knowledge, attitudes and practices were evaluated in a series of independent sample surveys in 2002, 2003, 2004 and 2005 , beginning in October every year ${ }^{(14)}$.

In the present paper we report only the short-term impacts of IHHP interventions on nutrition behaviour in the repeated cross-sectional study design in the intervention areas $v$. the reference area during these years, but because of some financial difficulties the fourth evaluation in 2005 was not done in the reference community.

\section{Dietary assessment}

Dietary behaviours were assessed with a validated, qualitative, forty-eight-item FFQ. As the present study is an intervention programme like the CINDI programme, the FFQ was adapted from the CINDI programme questionnaire ${ }^{(15)}$. Frequency responses could be scored as 2, 1 or 0 depending on nutritional value, with a higher score indicating higher total and saturated fat intakes. For example, for the question 'How many times a week do you usually eat meat, egg or whole dairy products?', a score of 0 was given to none or once per week, a score of 1 was given to two or three times weekly and a score of 2 was given for a frequency of four or more times weekly. A total score was calculated by summing the responses to individual questions. Score attribution was based on the cholesterol-saturated fat index, atherogenicity index for a specific food ${ }^{(16)}$, as well as the American Heart Association recommendations and the National Cholesterol Education Program ${ }^{(17)}$.

In the study, a global dietary index (GDI) of diet quality was calculated, representing the average of the mean of twenty-nine frequency questions in seven categories. A smaller GDI indicates better behaviour. The GDI was expected to decrease after the intervention activities. In addition to the GDI, two consumption indices were calculated for specific food groups: major sources of fat and meat products. These indices represent the mean of scores given to items from specific food groups. The fat consumption index (FCI) represents the mean of five frequency questions in five categories related to fat intake and the meat products consumption index (MCI) represents the mean of eight frequency questions in four categories related to meat intake. Table 1 shows how the GDI, FCI and MCI were calculated.

Table 1 Calculation of the global dietary index, fat consumption index and meat consumption index scores

\begin{tabular}{|c|c|c|c|c|}
\hline & & \multicolumn{3}{|c|}{ Score } \\
\hline & & 0 & 1 & 2 \\
\hline \multicolumn{5}{|c|}{ Global dietary index } \\
\hline 1 & How many times per week do you eat fast foods? (4 questions) & $0-1$ & 2-3 & 4 or more \\
\hline 2 & How many serving of fruits or vegetables do you eat in a week? (7 questions) & 28 or more & $14-28$ & Less than 14 \\
\hline 3 & How many times per week do you eat beans, chicken, soya protein or fish? (4 questions) & 3 or more & $1-2$ & Less than 1 \\
\hline 4 & How many times per week do you eat sweets? (6 questions) & $0-1$ & $2-3$ & 4 or more \\
\hline 5 & $\begin{array}{l}\text { How many times per week do you eat hydrogenated oil, ghee, animal fats or butter? } \\
\text { (4 questions) }\end{array}$ & $0-1$ & $2-3$ & 4 or more \\
\hline 6 & How many times per week do you eat meat, egg or whole dairy products? (4 questions) & $0-1$ & $2-3$ & 4 or more \\
\hline 7 & How many times per week do you eat non-hydrogenated oil, olive oil? (2 questions) & 7 or more & $5-6$ & Less than 5 \\
\hline \multicolumn{5}{|c|}{ Fat consumption index } \\
\hline 1 & How many times per week do you eat hydrogenated oil? (1 question) & 0 & $1-2$ & 3 or more \\
\hline 2 & How many times per week do you eat ghee? (1 question) & 0 & $1-2$ & 3 or more \\
\hline 3 & How many times per week do you eat butter? (1 question) & 0 & $1-2$ & 3 or more \\
\hline 4 & How many times per week do you eat animal fats? (1 question) & 0 & $1-2$ & 3 or more \\
\hline 5 & How many times per week do you eat non-hydrogenated oil? (1 question) & 4 or more & $1-2$ & Less than 1 \\
\hline 6 & How many times per week do you eat olive oil? (1 question) & 4 or more & $1-2$ & Less than 1 \\
\hline \multicolumn{5}{|c|}{ Meat consumption index } \\
\hline & How many times per week do you eat meat? (1 question) & $0-1$ & $2-3$ & 4 or more \\
\hline 2 & How many times per week do you eat sausages? (2 questions) & $0-1$ & $2-3$ & 4 or more \\
\hline & How many times per week do you eat liver, lung or kidney? (3 questions) & 0 & 1 & 2 or more \\
\hline & How many times per week do you eat chicken or fish? (2 questions) & 3 or more & $1-2$ & Less than 1 \\
\hline
\end{tabular}


The FFQ of CINDI was translated into Persian by a nutritionist. Foods that were not consumed in Iran were excluded and some typical Iranian foods, judged to be important contributors to total and saturated fat intake, were added. Face-content validity and translation of the questionnaire were assessed by an expert panel consisting of five nutritionists. The FFQ was pre-tested for clarity among 200 adults aged 19-69 years who were not subjects in the main study samples; they completed the questionnaire twice at a 2-week interval to assess the test-retest reliability $(r=0 \cdot 8)$. Criterion-related validity was assessed in 2400 subjects of the baseline sample by comparing the GDI score with a single $24 \mathrm{~h}$ diet recall. Subjects were visited at home by trained interviewers to complete a $24 \mathrm{~h}$ diet recall. Correlation coefficients of the GDI with energy intake from total fat and saturated fat were 0.39 and 0.45 , respectively.

\section{Statistical analyses}

Mean differences in BMI, age, FCI, MCI and GDI between the intervention and reference areas in each year were studied by the $t$ test. Analysis of covariance was conducted to compare variables of interest in each area during these years by considering other variables such as age, BMI, educational level and smoking status in the models to control confounding effects. Univariate ANOVA was conducted to evaluate the impact of the IHHP on dietary behaviours by analysing the interaction between year and group based on sex and settlement (urban or rural). The SPSS statistical software package version 15 (SPSS Inc., Chicago, IL, USA) was used to analyse the data. $P$ values less than 0.05 were considered significant.

\section{Results}

The total number of subjects studied comprised 12512 individuals in 2001, and 5891, 4793 and 6083 individuals in 2002, 2003 and 2004, respectively. Because of financial limitations, the fourth evaluation study in 2005 was done only in the intervention communities, on a population of 3010 individuals. Table 2 shows the population frequency of basic characteristics (sex, settlement, educational level and smoking status) in the intervention and reference areas. Figure 1 shows the secular trend of mean GDI in the total population. Mean GDI was reduced significantly in the intervention areas compared with the reference area, based on a significant year $\times$ group interaction coefficient $(P<0 \cdot 001)$.

As Table 3 shows, mean GDI was significantly lower in the intervention areas than in the reference community based on gender and settlement in each year. Mean GDI also showed a significant increase from baseline to the first evaluation $(P<0 \cdot 001)$; a mild increase in the reference area $(P<0.05)$ but a decrease in the intervention areas from the first to the second evaluation; and in the third evaluation

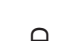

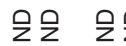

$\sum 2 \% \frac{1}{2}$

递灾

号

व

운

ஸ்

$\stackrel{1}{\check{1}}$

$e^{2}$

字

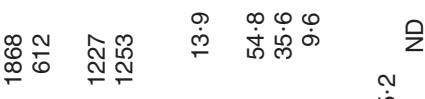

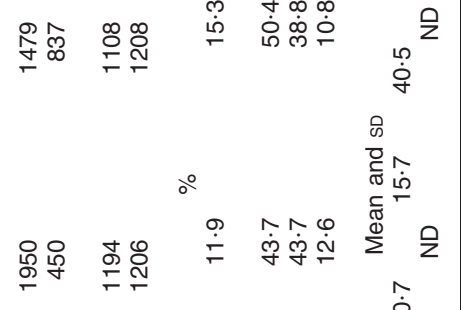

ம்

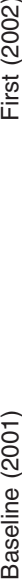

్ㅠㅇำ

டீ人 लिं

के

ì

$\frac{1}{2}$

字

妾

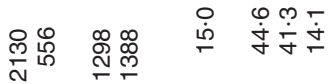

宇

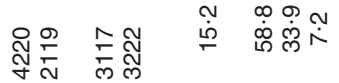

\section{움}

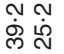

$\dot{\dot{v}} \stackrel{9}{\square}$

贝్

范

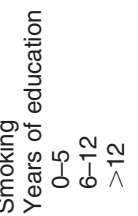




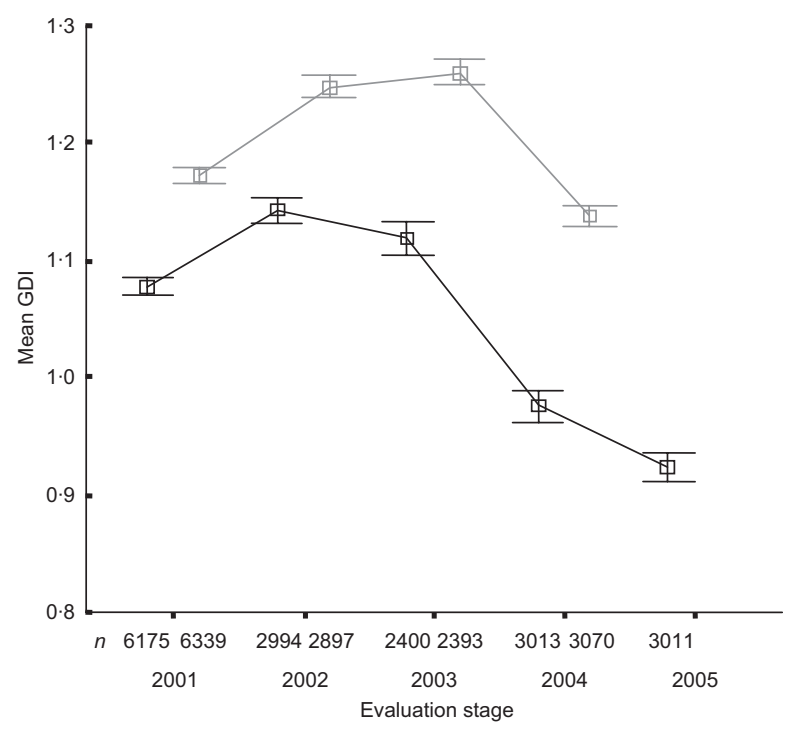

Fig. 1 Comparison of the trend in global dietary index (GDI) between the intervention $(-\square-)$ and reference $(-\square-)$ areas, 2001-2005: Isfahan Healthy Heart Programme, Iran. Values are means with standard deviation represented by vertical bars

study, despite the decrease in both areas, this decline was more in the intervention communities $(P<0 \cdot 001)$.

According to the significant year $\times$ group interaction coefficient for mean FCI in the total population, there was a significant improvement in FCI in the intervention areas $v$. the reference area $(P<0 \cdot 001$; Fig. 2).

Table 4 shows that the mean FCI was lower in the intervention areas than the reference area in each year $(P<0 \cdot 001)$; however, it showed a significant decrease in each area during these years $(P<0 \cdot 001)$. Although mean FCI appeared to reach a plateau from the third and the fourth evaluation study in the intervention areas, the difference between the intervention and the reference areas was not significant.

Figure 3 shows that the improvement in mean MCI was significantly more in the intervention areas than in the reference area $(P<0 \cdot 001)$. As Table 5 shows, although the trend of mean MCI decreased significantly in both areas, for each year it was lower in the intervention areas.

\section{Discussion}

The IHHP was effective in improving dietary behaviours as reflected in the GDI and consumption indices, especially the FCI. The programme had a local design and an impact on dietary behaviours, the same as previous heart health promotion programmes ${ }^{(18-21)}$. Compared with the North Karelia Project, which showed a reduction in SFA of $20 \%$ in men and $24 \%$ in women ${ }^{(22)}$, other programmes have shown lower population-wide changes ${ }^{(18-21)}$. Joint analysis of the combined evaluation data of the Stanford Project, the Minnesota Heart Health Program and the

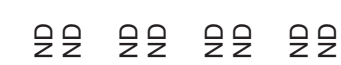

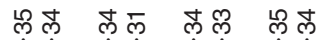

ó 00 ó 0 o

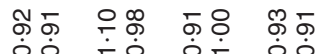

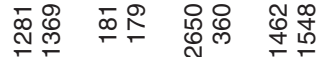

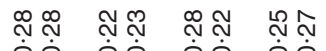

ó óo óo ó

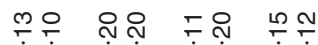

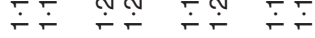

స్ㅇㅇㅇㅇ

尔等 웃 융

ळूल लू ले लिले

ó óo ó ó

絭粪

ó $\dot{0}$-́ ó

సิ์

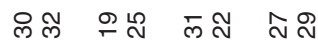

OO OO OO OO

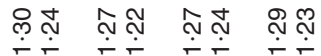

岗志

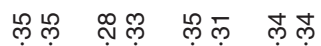

ó Oं Ó Oं

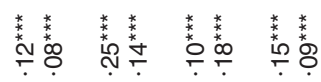

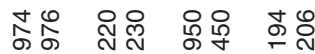

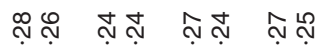

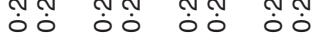

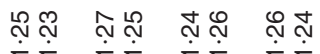

舟总

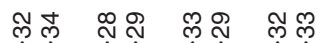

ठं 0 ó 0 ó

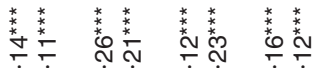

ர்

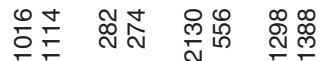

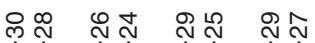

jo jó

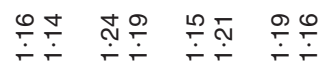

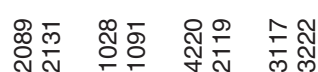

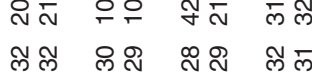

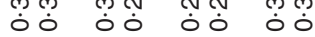

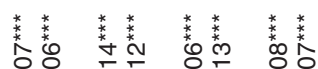

பு

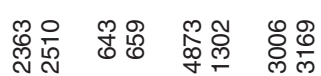

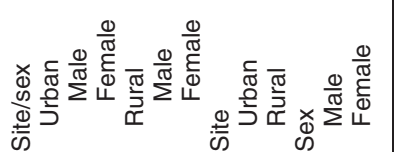




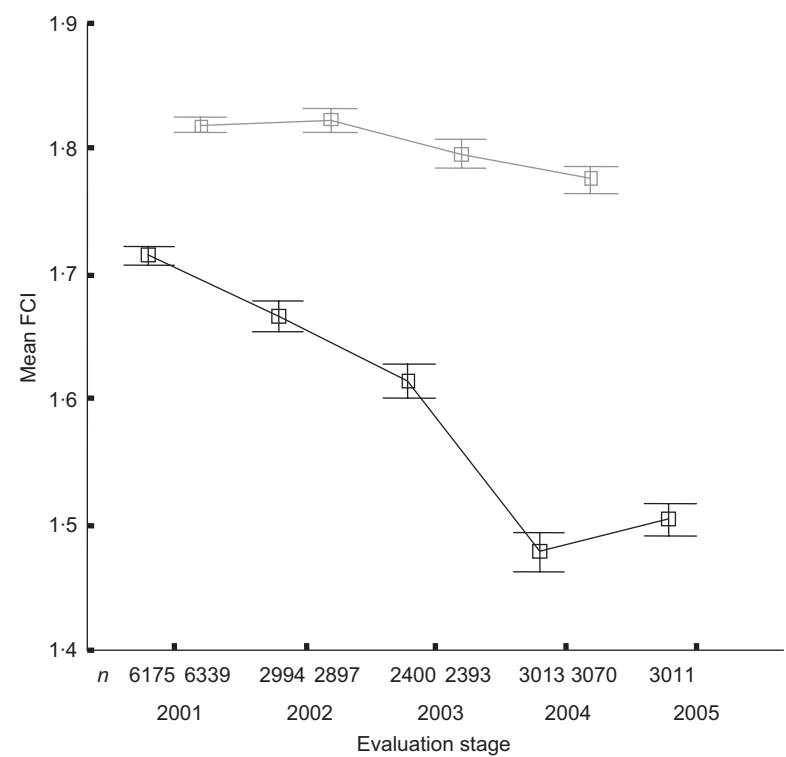

Fig. 2 Comparison of the trend in fat consumption index (FCl) between the intervention $(-\square-)$ and reference $(-\square-)$ areas, 2001-2005: Isfahan Healthy Heart Programme, Iran. Values are means with standard deviation represented by vertical bars

Pawtucket Heart Health Program did not show any global acceptable impact on the main dietary variables, suggesting that statistical power was not an issue in the evaluation of the individual programmes ${ }^{(23)}$. In addition, a Quebec 4-year community-based programme could not show any impact on high-fat/junk food consumption ${ }^{(24)}$.

At baseline in our study, GDI, FCI and MCI values in the intervention areas were significantly lower than those in the reference community. This can be considered a result of the small cultural difference between the intervention and reference areas, although we tried to choose similar communities. However, as the changes in GDI, FCI and MCI were compared during the years, our results were not confused. A significant secular trend was found in FCI, GDI and MCI, which revealed an improvement in fat consumption, overall diet and meat consumption, respectively. Trans fatty acid intake is the most important dietary factor in CVD incidence and hydrogenated oil is the main dietary source of this fatty acid ${ }^{(25)}$. Based on a previous study, hydrogenated oils produced in Iran contain 30-40\% trans fatty acids and also $89 \%$ of the Iranian population consumes hydrogenated oil ${ }^{(26)}$; so a reduction in trans fatty acid consumption was defined as the main nutritional objective in the $\operatorname{IHHP}^{(7)}$. To implement this objective, some intervention activities were conducted, including co-operation with the Isfahan Commerce Office to substitute hydrogenated oil distribution with liquid oil by coupon; educating people to not use hydrogenated oil by mass media and health professionals; and co-operation with oil factories in order to help them produce liquid oil instead of hydrogenated oil or to decrease the trans fatty acid content of the oils

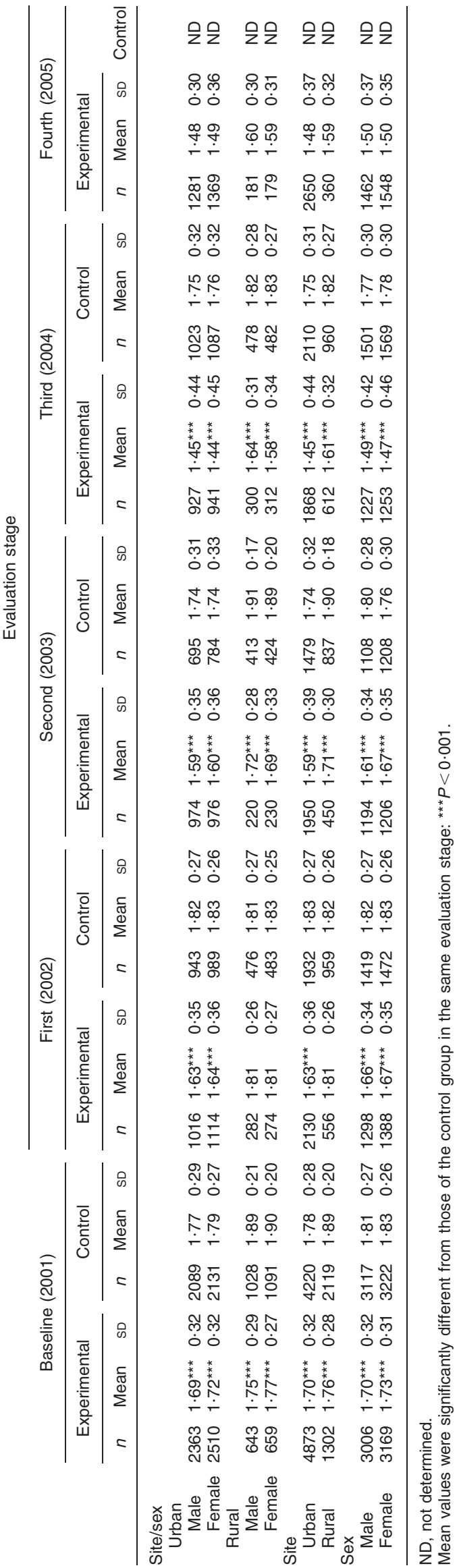




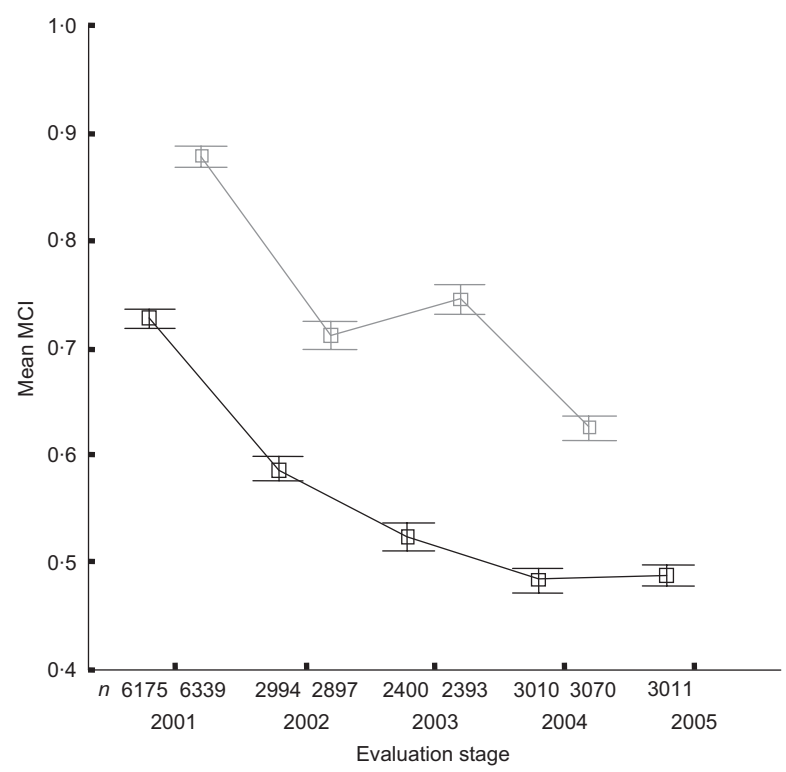

Fig. 3 Comparison of the trend in meat consumption index (MCl) between the intervention ( $-\square-$ ) and reference $(-\square-)$ areas, 2001-2005: Isfahan Healthy Heart Programme, Iran. Values are means with standard deviation represented by vertical bars

made. As IHHP intervention activities were not done in the reference area, the trend of FCI was a plateau in this community; therefore the significant decrease in FCI in the intervention areas showed the acceptable effect of the IHHP intervention activities on dietary fat consumption.

The trends in MCI showed that intervention activities can improve meat, poultry and fish consumption, i.e. they can increase fish and poultry consumption and decrease meat consumption frequency. As meat consumption in the Iranian population is not generally high, we focused on meat less than on oil in the IHHP; however, one of our intervention activities was increasing fish consumption. The high decrease in MCI in the reference area might be caused by a concurrent national health programme, including public education by mass media such as television, magazines and newsletters, independent from IHHP activities.

The GDI increased after one year of intervention in 2002, and it also improved after the second year of intervention; so the GDI might need more time to improve. Although the results showed a significant improvement in GDI and consumption indices in the intervention areas, the secular trend had the same direction in both areas, likely a result of other intervention activities that were in progress in the whole country parallel to the IHHP. The countrywide intervention activities were focused mainly on public education by mass media.

Strong secular trends towards in fat reduction have been shown in North America since the beginning of the North Karelia Project in 1970. Canadian adults decreased their dietary fat intake from $40 \%$ to $30 \%$ during

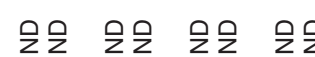

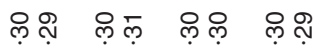

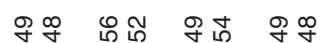

ó ó ó ó ó

뜜욤

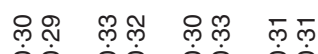

óo óó óó ó

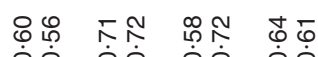

ó ó ó ó ó

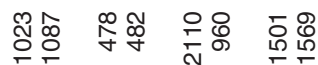

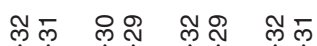

ó ó ó ó ó

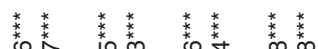

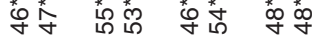

ó 0ं ó ó ó

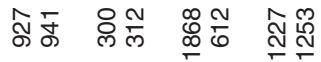

फ्ल

ó 0ं ó 0 0

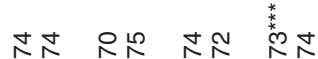

ó $\dot{0}$ ó

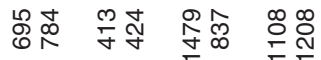

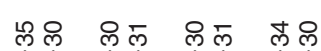

ó ó ó ó 0

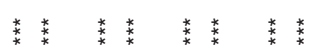

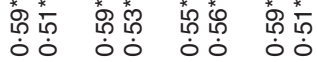

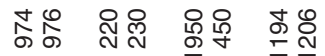

मेल लु मेल मे एल

ó ó ó ó ó

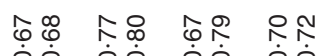

óo óó Óó ó

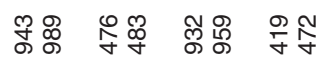

ల్లా న్ స్ల ల్ల స్లె

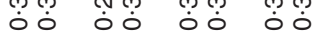

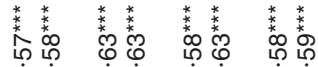

ó ó ó ó

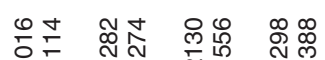

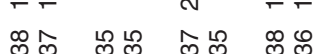

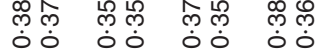

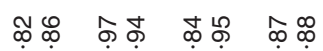

ó ó ó ó ó

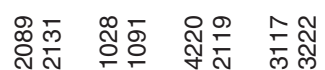

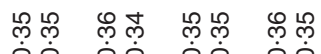

Ó Ó Ó Ó Ó

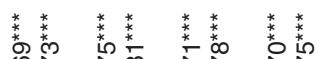

$\frac{1}{1}$

ó ó ó ó

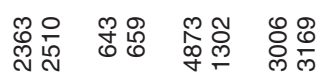

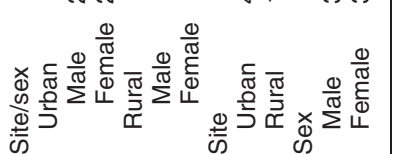

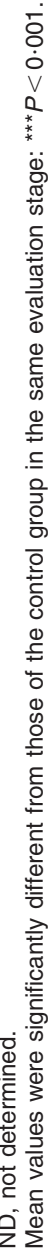


1970-8 ${ }^{(27)}$. In Quebec, nutrition assessments have shown that men aged 35-49 years reduced their fat intake from $37 \cdot 0 \%$ to $34 \cdot 0 \%$ and women from $37 \cdot 5 \%$ to $33 \cdot 4 \%$, during 1970-90(13). Also, SFA intakes decreased from $15 \cdot 2 \%$ to $12 \cdot 9 \%$ in men and from $15 \cdot 4 \%$ to $12 \cdot 2 \%$ in women $^{(13)}$.

\section{Study limitations and strengtbs}

Cross-sectional, independent samples were used in the present study despite the fact that a cohort sample shows greater statistical significance ${ }^{(28)}$. The FFQ is subject to bias due to the limited food list, the choice of frequency categories and the difficulty in remembering foods eaten in the past ${ }^{(29)}$; moreover, as the FFQ employed was qualitative, the estimation of dietary intake was not exact. In addition to these limits, dietary behaviours are subject to recall or report bias ${ }^{(30)}$. On the other hand, the longitudinal nature of the data and the novelty of the data and the programme in a developing country are the main strengths of the present study. Although we tried to choose the intervention and reference areas to be similar in health profile, there was a small difference between these two areas; however, as we compared their dietary behaviour changes during the years, this limitation did not confuse the results.

\section{Conclusion}

The IHHP interventions were effective in improving dietary behaviours at the population level. The greatest effectiveness was seen for the FCI, as a representation of fat consumption. Since these simple and integrated interventions were effective, they can be disseminated in other communities.

\section{Acknowledgements}

We have no conflicts of interest. N.M. wrote the paper and co-operated in designing and managing the studies, and conducting the intervention activities and evaluation studies; R.K. co-operated in designing the study and writing the paper; M.S. co-operated in conducting the intervention activities; N.S. co-operated in designing and managing the study; F.S. co-operated in conducting the intervention activities and evaluation studies; G.H.S. co-operated in designing and managing the study; M.M. co-operated in conducting the intervention activities and evaluation studies; H.A. co-operated in conducting the intervention activities and evaluation studies; S.H. co-operated in conducting the evaluation studies; F.S. co-operated in conducting the intervention activities. The Organization of Planning and Management, the Deputy for Health of the Iranian Ministry of Health, Treatment, and Medical Education, and the Isfahan Cardiovascular Research Center funded the study. We thank Isfahan
Provincial Health Center and Arak Health Center who helped us in performing the study and Miss Hengameh Nouri for her help with statistical analysis.

\section{References}

1. Anon. (1993) Cardiovascular disease mortality in the developing countries. World Health Stat Q 46, 89-150.

2. Sarraf-Zadegan N, Boshtam M \& Rafiei M (1999) Risk factors of coronary heart disease in urban in Isfahan. Eur J Public Health 9, 20-26.

3. Sarraf-Zadegan N, Boshtam M, Malekafzali H, Bashardoost N, Sayed-Tabatabaei FA, Rafiei M, Khalili A, Mostafavi S, Khami M \& Hassanvand R (1999) Secular trends of mortality from cardiovascular disease in Iran: with special reference to Isfahan. Acta Cardiol 54, 327-333.

4. Puska P, Salonen J \& Nissinen A (1983) Change in risk factors for coronary heart disease during 10 years of community intervention program: North Karelia Project. Br Med J 287, 1840-1844.

5. Sparaka JM, Burke GL, Folsom AR, Luepker RV \& Blackburn H (1990) Continued decline in cardiovascular disease risk factors: results of the Minnesota Heart Survey, 1980-1982 and 1985-1987. Am J Epidemiol 132, 489-500.

6. Ornish D, Brown SF \& Sherwitz LW (1990) Can lifestyle changes reverse coronary heart disease? The Lifestyle Heart Trial. Lancet 336, 129-133.

7. Sarraf-Zadegan N, Sadri G, Malek Afzali H et al. (2003) Isfahan Healthy Heart Programme: a comprehensive integrated community-based programme for cardiovascular disease prevention and control. Design, methods and initial experience. Acta Cardiol 58, 309-321.

8. Kant AK (1996) Indexes of overall diet quality: a review. J Am Diet Assoc 96, 785-791.

9. Gerber M (2001) The comprehensive approach to diet: a critical review. J Nutr 131, Suppl. 11, 3051S-3055S

10. Hann CS, Rock CL, King I \& Drewnowski A (2001) Validation of the Healthy Eating Index with use of plasma biomarkers in a clinical sample of women. Am J Clin Nutr 74, 479-486.

11. Kant AK, Schatzkin A \& Ziegler RG (1995) Dietary diversity and subsequent cause-specific mortality in the NHANES I epidemiologic follow-up study. J Am Coll Nutr 14, 233-238.

12. Patterson RE, Haines PS \& Popkin BM (1994) Diet Quality Index: capturing a multidimensional behaviour. J Am Diet Assoc 94, 57-64.

13. Huot I, Paradis G \& Ledoux M (2004) Effects of the Quebec Heart Health Demonstration Project on adult dietary behaviors. Prev Med 38, 137-148.

14. Sarrafzadegan N, Baghaei AM, Sadri GH et al. (2006) Isfahan Healthy Heart Program: evaluation of comprehensive, community-based interventions for non-communicable disease prevention. Prev Control 2, 73-84.

15. Leparki E \& Nussel E (1987) CINDI: Countrywide Integrated Non-Communicable Diseases Interventional Programme: Protocol and Guidelines for Monitoring and Evaluation Procedures, pp. 73-82. Berlin: Springer-Verlag.

16. Connor SL, Gustafson JR, Artaud-Wild SM, Flavell DP, Classick-Kohn CJ, Hatcher LF \& Connor WE (1986) The cholesterol/saturated fat index: an indication of the hypercholesterolaemic and atherogenic potential of food. Lancet 1, 1229-1232.

17. National Cholesterol Education Program (NCEP) Expert Panel on Detection, Evaluation, and Treatment of High Blood Cholesterol in Adults (Adult Treatment Panel III) (2002) Third Report of the National Cholesterol Education Program (NCEP) Expert Panel on Detection, Evaluation, 
and Treatment of High Blood Cholesterol in Adults (Adult Treatment Panel III) final report. Circulation 106, 3143-3421.

18. Fortmann SP, Taylor CB, Flora JA \& Winkleby MA (1993) Effect of community health education on plasma cholesterol levels and diet: The Stanford Five-City Project. Am J Epidemiol 137, 1039-1055.

19. Luepker RV, Rastam L, Hannan PJ et al. (1996) Community education for cardiovascular disease prevention. Morbidity and mortality results from the Minnesota Heart Health Program. Am J Epidemiol 144, 351-362.

20. Carleton RA, Lasater TM, Assaf AR, Feldman HA \& McKinlay S (1995) The Pawtucket Heart Health Program: community changes in cardiovascular risk factors and projected disease risk. Am J Public Health 85, 777-785.

21. Tudor-Smith C, Nutbeam D, Moore L \& Catford J (1998) Effects of the Heartbeat Wales program over five years on behavioural risks for cardiovascular disease: quasi-experimental comparison of results from Wales and a matched reference area. BMJ 316, 818-822.

22. Pietinen $\mathrm{P}$, Nissinen A, Vartiainen E, Tuomilehto A, Uusitalo U, Ketola A, Moisio S \& Puska P (1988) Dietary changes in the North Karelia Project (1972-1982). Prev Med 17, 183-193.

23. Winkleby MA, Feldman HA \& Murray DM (1997) Joint analysis of the three US community intervention trials for reduction of cardiovascular disease risk. J Clin Epidemiol 50, 645-658.

24. O'Loughlin JL, Paradis G, Gray-Donald K \& Renaud L (1999) The impact of a community-based heart disease prevention program in a low-income, inner-city neighborhood. Am J Public Health 89, 1819-1826.

25. Mozafarian D, Katan MB, Ascherio A, Stampfer MJ \& Willett WC (2006) Trans acids and cardiovascular disease. N Engl J Med 354, 1601-1613.

26. Bahrami GH \& Mirzaeei SH (2003) The evaluation of fatty acids profile in available hydrogenated oils and margarines in Iran. Iranian Heart J 4, 59-67.

27. Gray-Donald K, Jacobs-Starkey L \& Johnson-Down DL (2000) Food habits of Canadians: reduction in fat intake over a generation. Can J Public Health 91, 381-385.

28. Diehr P, Martin DC, Koepsell T, Cheadle A, Psaty BM \& Wagner EH (1995) Optimal survey design for community intervention evaluations: cohort or cross-sectional? J Clin Epidemiol 48, 1461-1472.

29. Willett WC (1990) Nutritional Epidemiology. Monographs in Epidemiology and Biostatistics. New York: Oxford University Press.

30. Hebert JR, Clemow L, Pbert L, Ockene IS \& Ockene JK (1995) Social desirability bias in dietary self-reported may compromise the validity of dietary intake measures. Int $J$ Epidemiol 24, 389-398. 